\title{
Balıkesir Bölgesine ait jips(alçıtaşı) örneğinin karakteristik özellikleri ve kullanım alanları
}

\author{
Öykü Bilgin ${ }^{1 *}$ \\ ${ }^{1}$ Şırnak Üniversitesi, Mühendislik Fakültesi, Maden Mühendisliği Bölümü, Şırnak-TÜRKIYY, (ORCID: 0000-0002-1276-5751)
}

(İlk Geliş Tarihi 12 Aralık 2018 ve Kabul Tarihi 16 Şubat 2019)

(DOI: $10.31590 /$ ejosat.495916)

ATIF/REFERENCE: Bilgin, Ö. (2019). Balıkesir Bölgesine ait jips(alçıtaşı) örneğinin karakteristik özellikleri ve kullanım alanlar1. Avrupa Bilim ve Teknoloji Dergisi, (15), 55-60.

\begin{abstract}
$\ddot{O} \mathbf{z}$
Jips(Alçıtaşı) kimyasal bileşimi kalsiyum sülfat $\left(\mathrm{CaSO}_{4} \cdot 2 \mathrm{H}_{2} \mathrm{O}\right)$ olan bir mineral çeşididir. Türkiye' nin çeşitli illerinde jips yatakları milyonlarca ton rezervlerde bulunmaktadır. Başlıca maden yataklarından birisi de Balıkesir-Susurluk Jips sahası olup, yaklaşık 1.000.000 ton rezerve sahip olduğu bilinmektedir. Jipsin kullanım alanları oldukça geniştir. Bunların en önemlileri arasında; beyaz boya ve dolgu malzemesi yapımı, çimento sanayi, tıp, dişçilik, kimya sanayi ve tarımda toprak düzenleyicisi olarak kullanımı yer almaktadır. Alçı taşı üretimi ele alınırsa, açık işletme veya kuyu-galeri şeklinde yapılmaktadır. Ocaktan gelen ham cevher genellikle kırıcılarda istenilen boyuta indirildikten sonra firında maksimum $160{ }^{\circ} \mathrm{C}$ ' de $2-3$ saat 1 sıl işleme tabi tutulduktan sonra yakılan alçı taşı soğutulup, öğütülür ve torbalanarak satışa sunulmaktadır. Bu çalışmada; Balıkesir bölgesine ait Jips(Alçıtaşı) örneğinin kimyasal analizleri, yoğunluk analizleri, ince kesit analizleri, SEM görüntüleri ve X-Ray analizleri yapılarak karakteristik özellikleri belirlenmiştir.
\end{abstract}

Anahtar Kelimeler: Jips, alçıtaşı, karakterizasyon, Balıkesir

\section{Characteristic properties of gypsum sample of Balıkesir Region and its usage areas}

\begin{abstract}
The gypsum (plaster) chemical compound is a mineral variety with calcium sulphate $\left(\mathrm{CaSO}_{4} \cdot 2 \mathrm{H}_{2} \mathrm{O}\right)$. In Turkey, there are reserves millions of tons of gypsum deposits in various provinces. One of the major mineral deposits is Balikesir-Susurluk Gypsum and it is known that it has about 1.000.000 tons reserves. The fields of use of gypsum are quite extensive. Among the most important ones are; white paint and filling materials, cement industry, medicine, dentistry, chemical industry and agriculture as soil regulator. If gypsum production is considered, it is constructed as open pit or well-gallery. The raw ore coming from the quarry is usually crushed at the desired size in the crushers. Then it is heat treated for 2-3 hours at maximum $160{ }^{\circ} \mathrm{C}$ in the oven. The burned gypsum is cooled, milled and bagged for sale. In this study; the sample of gypsum (Balıkesir-gypsum) has been determined chemical analysis, density analysis, thin section analysis, SEM images and X-ray analyzes.
\end{abstract}

Keywords: Gypsum, plaster, characterization, Balikesir

\footnotetext{
* Sorumlu Yazar: Şırnak Üniversitesi, Mühendislik Fakültesi, Maden Mühendisliği Bölümü, Şırnak-TÜRKIYE, ORCID: 0000-0002-1276-5751, ykbilgin@yahoo.com
} 


\section{Giriș}

Jips(Alçıtaşı)' nın kimyasal olarak iki molekül kristal suyu bulunan türü kalsiyum sülfat (CaSO4.2H2O) olarak tanımlanmaktadır[1,2]. Alçıtaşı doğada altı türde bulunmaktadır. Bunlar; Jips, Anhidrit, İpek Jipsi Bassanit, Albatr, ve Selenit'tir. Alçı taşı büyük oranda anhidrit (CaSO4) susuz veya dihidrat $(\mathrm{CaSO} 4.2 \mathrm{H} 2 \mathrm{O})$ şeklinde ayrılmaktadır[3]. Diğer bir tanımla alçı; CaSO4. $1 / 2 \mathrm{H} 2 \mathrm{O}$ (yarım hidrat) formülü ile ifade edilmektedir ve jipsin $120^{\circ} \mathrm{C}$ civarında yakılmasıyla elde edilmektedir[4]. Jips; bünyesinde 2 molekül su içermesi ve genellikle kayaç halinde masif bir şekilde bulunması sebebiyle anhidritten kolayca ayırt edilebilir, çünkü anhidrite göre çok yumuşaktır ve tırnakla kolayca çizilebilir. Jipsin mohs cetveline göre sertliği 2 civarında olmasına karşın Anhidritin sertliği 3-3,5 arasında değişir. Yine Jipsin özgül ağırlığı 2,2-2,4 arasında olduğu halde Anhidritin özgül ağırlığ 2,7-3,0 arasında değişmektedir. Jipsin rengi genelde beyaz veya beyazımsı kül rengindedir. Jipsin içindeki yabancı maddeler jipse ve ondan elde edilecek alçıya da renk verirler[3].

Alçı taşı dünya çapında çok geniş yataklara sahiptir. Dünyada büyük miktarlarda jips rezervine sahip olan ülkeler ABD, Fransa, Rusya, İngiltere, Kanada ve Türkiye'dir. Türkiye'deki jips yataklarında bulunan jipslerin saflı̆̆ı batı ülkelerindekine nazaran çok iyidir. Batı ülkelerinde \% 70 saflıkta jipsler kullanılırken bu oran Türkiye'de \% 95-99 civarındadır[3]. Tablo1' de Türkiye'de bilinen jips(alçıtaşı) potansiyeli bulunan illerin listesi gösterilmektedir.

Tablo 1. Türkiye'de jips(alçıtaşı) potansiyeli bulunan iller [5,6]

\begin{tabular}{|c|l|}
\hline Ankara & $\begin{array}{l}\text { Ayaş-Beypazarı, Bala-Aşıkoğlu, Polatlı-Sazılar, } \\
\text { Bahçe-Karadalak,Şereflikoçhisar-B.Kışla, } \\
\text { Kurutlutepe, Bala-Sarıpınar, Çiğdemli, Emirdağ- } \\
\text { Gülçayır, Çayırhan Termik Santrali(sentetik) }\end{array}$ \\
\hline Bolu & Bakacak \\
\hline Balıkesir & Susurluk \\
\hline Bandırma & Bağfaş Gübre Fabrikası(sentetik) \\
\hline Amasya & Vezirköprü-Adatepe, Akören \\
\hline Bursa & $\begin{array}{l}\text { Gemlik-Adliye, Hamidiye, Orhaneli Termik Santrali } \\
\text { (Sentetik) }\end{array}$ \\
\hline Aydın & Yazıkent-Karaahmetler \\
\hline İzmit & Fürsan Gübre Fabrikası(sentetik) \\
\hline Karabük & Ovacık-Pürçükören \\
\hline Muğla & Yatağan Termik Santrali (sentetik) \\
\hline Adana & Yumurtalık Toros Gübre Fabrikası (sentetik) \\
\hline Çorum & Çukurköy Bayat-Emirhalil, Üçdam, Tuğlu \\
\hline Erzurum & Aşkale \\
\hline Siirt & Kurtalan \\
\hline Sivas & Ulaş-Çiftağıllar \\
\hline Niğde & Ulukışla-Emirler, Darboğaz \\
\hline Kütahya & Gediz-Akçaalan, Yayla, Gökler \\
\hline Eskişehir & Sivrihisar-Biçer \\
\hline Kırıkkale & $\begin{array}{l}\text { Keskin-Halitli, Delice-Tavaözü, Delice-Akboğaz, } \\
\text { Kuzucak }\end{array}$ \\
\hline Denizli & $\begin{array}{l}\text { Sarayköy-Yeşilyurt, Buldan-Derbent, Alacaoğlu, } \\
\text { Güney-Aksaz, Honaz-Kızılyer }\end{array}$ \\
\hline Mersin & Tarsus-Dadalı, Karayayla, Tepeçaylak \\
\hline Adana & Solbaş \\
\hline Hatay & Arsuz \\
\hline
\end{tabular}

Türkiye'nin jips rezervi milyonlarca tondur. Başlıca rezerv sahaları; Beypazarı Havzası, Tuzgölü havzası, Çankırı Çorum-Yozgat havzası, Karabük-Pürçükören, Sivas havzası, Güneydoğu Anadolu havzası, Kars Kağızman-Tuzluca, Erzurum çevresi, Denizli çevresi, Balıkesir susurluk sahası ve Kütahya-Gediz sahasıdır [3]. Türkiye'de yer alan alçıtaşı maden işletmeleri genel olarak, Ankara(Beypazarı, Şereflikoçhisar, Ayaş ilçeleri) Balıkesir-Susurluk, Niğde-Ulukışla, Eskişehir-

Sivrihisar, Denizli-Honaz ve Erzurum-Aşkale şeklinde sıralanabilir[7]. Alçııtaşı rezervleri ayrıca Güney, İç Anadolu, ve Güney Doğu Anadolu'da yaygın bir şekilde mevcuttur[8].Yapılan kaynak araştırmalarına göre Balıkesir-Susurluk-Demirkapı yaklaşık 1.000.000 ton civarında jips rezervleri gözlenmiştir[9]. Ankara-Beypazarı havzasında 1 milyar tondan fazla alçıtaşı rezervlerinin olduğu yapılan araştırmalara göre tahmin edilmektedir [10,2]. VI. Beş Yıllık Kalkınma Planı Alçı Özel İhtisas Komisyon raporuna göre; MTA' nın tahmini verilerinde alçıtaşı görünür rezervinin yaklaşık 165 milyon ton ve muhtemel rezervi de1.8 milyar ton olduğu belirtilmiştir[5]. Bu çalışmada Balıkesir-Susurluk sahasından alınan Jips örneğinin karakteristik özellikleri ve kullanım alanları araştırılmaktadır.

\section{Materyal ve Method}

\subsection{Balıkesir-Susurluk jips oluşumlarının jeolojisi}

Balıkesir-Susurluk bölgesinde jips yatakları, kalın tabakalı ve geniş bir alanda yayılmış olduklarından bu neojen evaporit havzası "Sultançayır Boratlı Jips Havzası" olarak adlandırılmaktadır. Batı Anadolu'da yer alan diğer borat havzalarına benzer şekilde bu havza da kuzey-güney uzanımlıdır. Kestelek-Sultançayır borat havzasının, mineral oluşumları incelendiğinde jips, kireçtaşı, kiltaşı, ve tüfler ile ardalanmalı pandermit minerallerinin, nadir olarak kolemanit ve havlit minerallerinin bulunduğu tespit edilmiştir[11]. Alt kireçtaşı birimi, yanal yönde kumlu kiltaşı birimine geçiş gösterirken, kumlu kiltaşı birimi, alttan üste doğru sırasıyla kumlu kiltaşı, kiltaşı, boratl jipsler, tüftüfit, kumlu kiltaşı ve karbonatlı kiltaşlarından oluşan volkano-sedimenter bir oluşum meydana getirmektedir. Ayrıca 
Demirkapı'nın doğusundan başlayan Hasantepe sırtlarında boratlı jipslerin varlığı görülmüştür. Jipsler, alttan üste doğru, tabakalı boratlı jips, jipsli boratlar, boratlar, tabakalı jips, grimsi yeşil kiltaşları, tüf-tüfit ve en üstte tabakalı jipsler şeklinde sıralanarak oluşum göstermektedir. Diğer taraftan yaklaşık 1-1,5 m kalınlığındaki jipsli killer; jipsleri alt ve üst olmak üzere iki zon halinde ayrılmaktadır. Boratlı jipslerin içerisinde tüf - tüfit ara katmanları yer yer gözlenirken, evaporasyon boyunca volkanizmanın aktif söylenebilir. Tabanı gözlenemeyen görünür jipslerin kalınlıkları yaklaşık 10 - 15 m arasındadır. Masif jipsler içerisinde gözlenen boratlar, merceksel ve nodüler şekilli beyaz renkli pandermit ve nodüler havlit mineralleri halinde oluşum sağlamıştır. Kumlu kiltaşı birimi içerisinde kalınlığı 10-15 m civarında boratlı jipsler yer almaktadır. Sözkonusu jipslerin içerisinde nodüller şekilli pandermit ve havlit mineralleri mevcuttur. Yapılan çalışmalara göre, tespit edilen jipslerin yaklaşık 300 milyon ton rezerve sahip olabileceği sonucuna varılmıştır. Ayrıca $\mathrm{SO}_{3}$ oranları \% 34'ün üzerinde olan bu jipslerin, çimento sektöründe kullanıma uygun değerlerde olduğu sonucuna varılmıştır[12].

\subsection{Jips(alçıtașı)nın kullanım alanları}

Jips(alçıtaşı) genellikle \%80-85 yapı alçısı üretimi, \%10-15 endüstriyel kullanım (çimento üretimi, sondaj, kalıpçılık, cam, hayvan yemi, böcek ilacı, tutkal, boya, plastik üretimi, gıda, eczacılık vb.)ve \%25 zirai amaçlı olarak kullanılmaktadır[3]. Toprak düzenleyici olarak kullanılan doğal jips; toprak ıslah edici, toprağı düzenleyici, toprak kalitesini arttırıcı özelliktedir. Diğer bir deyişle jips kullanılan toprakların tuz ve kireç oranları azalarak yıpranmış topraklar sslah edilmektedir. Böylece toprak gevşeyerek, su tutma özelliği artırır ve pH dengesi ayarlanır, kalsiyum ve kükürt oranı da zenginleşir. Ayrıca faydalı mikroorganizmaların çoğalmasına ortam hazırlar, iyon alışverişini arttırır, bitki besin maddelerinin kaybını ve yeraltı sularına karışmasını önleyerek, suları toksik etkilerden korumaktadır[13,14]. Jips; beyaz boya ve dolgu maddesi olarak kağıt ve pamuklu tekstil maddelerinde katkı maddesi olarak kullanılmaktadır. Çimento sektöründe jips kullanımı prizlenmeyi geciktirmesi, nikel izabesinde eritmeyi kolaylaştırması şeklinde sıralanabilir. Alçı, tıp alanında cerrahi ve dişçilik uygulamalarında, porselen, vitrifiye malzemeler ve kiremit üretiminde kullanılmaktadır. Diğer taraftan kimyasal reaktiflerin (amonyum sülfat, kükürt, kükürt okside ve sülfat asidi vs.) eldesinde, inşaat ve prefabrik malzemelerin, bira yapımında mayalandırma işlemlerinde, sıcak-soğuk yalıtım malzemesi, ses izolatörü ve rutubeti de ayarlayıcı olarak kullanım alanları mevcuttur[6]. Termik santraller ve gübre fabrikalarında bulunan baca gazı arınndırma ünitelerinden sentetik alçı üretimi yapılmaktadır[8]. Türkiye' de üretilen pek çok alçıtaşı ürünleri T.S.E. tarafından uluslararası standartlarda Dünya' da yerini almıştır. Üretilen alçı ürünleri başlıca kalıp alçıları(teksir, porselen, seramik, kiremit), tıp alanında(diş, ortopetik), inşaat sektöründe (inşaat, saten perdah, kartonpiyer, makine sıva, perlitli sıva, dolu gövdeli duval blok, derz dolgu, iki yüzü kartonlu alçı plaka) ve alçıtaşı (mikronize, tüvenan, vb.)' dir [6,15].

\subsection{Jips(alçıtaşı) üretim ve teknolojisi}

Alçıtaşı madencilik yöntemleri olarak genellikle açık işletme veya kuyu-galeri şeklinde yapılmaktadır. Ocaktan gelen ham cevher elle veya mekanik kırıcılar yardımı ile kırıldıktan sonra kullanılacak fırının özelliğine göre istenilen tane boyutuna indirgenir. Daha sonra numuneler $3 \times 4 \mathrm{~m}$. silindir şekilli torbaların içerisinde ortalama 2-2,5 saat süre ile maksimum $160^{\circ} \mathrm{C}$ sicaklıkta 1 sıl işleme tabi tutulur. Yakılan alçı taşı soğutulup, ögütüldükten sonra uygun şekilde torbalanmaktadır[4]. Türkiye'de birçok alçı üretim teknolojileri uygulanmaktadır. Örneğin inşaat sektöründe kullanılan yap1 alçısı üretimi açık atmosfer ortamında kalsinasyon yöntemi ile yapılmaktadır. Bu yöntem için özellikle dikey firın ve döner firın teknolojileri kullanılmaktadır. Alçı, alçı taşının (kalsiyum sülfat dihidrat) öğütülüp $192{ }^{\circ} \mathrm{C}$ sıcaklıkta suyunun \% 76 oranında atılmasıyla elde edilmektedir. Tüvenan alçı taş1 0-50 cm, kırılmış alçıtaşı 0-16 cm aralığında veya isteğe göre değişik boyutlarda kırılabilmektedir. Öğütülmüş mikronize alçı taşı boyutları 0-100 Mikron yada 200- 800 Mikron ya da istenen tane boyutlarında elde edilebilmektedir[16].

Sıcaklık artışına bağlı olarak alçıtaşının kristal suyu kaybı oranını ve elde edilen ürünler aşağıdaki şekilde gerçekleşmektedir:

- Alçıtaşı $95-165^{\circ} \mathrm{C}$ arasındaki sıcaklıklarda bünyesinde bulunan kristal suyunun yaklaşı \% \% 75 'ini kaybetmektedir ve buna bağlı olarak ağırlığ $\% 15,68$ oranında azalmaktadır. $\mathrm{CaSO}_{4} \cdot 2 \mathrm{H}_{2} \mathrm{O}=\mathrm{CaSO}_{4} \cdot 1 / 2 \mathrm{H}_{2} \mathrm{O}+3 / 2 \mathrm{H}_{2} \mathrm{O}$ formülünde elde edilen ürün kalsiyum sülfat yarım hidratdır ve alçının ham maddesini oluşturur.

- Alçıtaşı $190-210{ }^{\circ} \mathrm{C}$ 1sıtıldığında bünyesindeki kristal suyunun tamamını kaybetmektedir ve ağırlığı da yaklaşık \%20.90 oranında azalmaktadır. $\mathrm{CaSO}_{4} .1 / 2 \mathrm{H}_{2} \mathrm{O}=\mathrm{CaSO}_{4}+1 / 2 \mathrm{H}_{2} \mathrm{O}$ formülünde elde edilen ürüne Anhidrit III veya Çözünür Anhidrit adı verilmektedir. Anhidrit neme karşı duyarlı olduğundan sanayide kurutucu şeklinde kullanılmaktadır.

- $\quad 340-480{ }^{\circ} \mathrm{C}$ arasındaki sıcaklıkta ekzotermik bir reaksiyon gelişmektedir ve Anhidrit III, Anhidrit II veya Çözünemez Anhidrit adı verilen bir maddeye dönüşmektedir. Bu madde çimento üretiminde kullanılan bir katkı malzemesidir.

- Anhidrit II maddesi 1sıtılmaya devam edildiğinde 900-1200 ${ }^{\circ} \mathrm{C}$ arasındaki sıcaklıklarda Anhidrit $\mathrm{F}^{\prime}$ ye dönüşmektedir. Bu sıcaklıklarda malzeme akkor hale gelmektedir, kalsiyum sülfat ayrışmaktadır ve içeriğinde yer alan sülfürü $\mathrm{S}_{2}$ gazı olarak serbest bırakmaktadır. Böylece malzeme içeriğindeki kalsiyum oksit oranı artmaktadır. Anhidrit I, suyla karıştığında alçıtaşı, diğer ürünlere göre daha yavaş katılaşmaktadır. Katılaşan malzeme daha sert, yoğun ve mukavemetli bir kütle haline gelmektedir [2,17].

\section{Araştırma Bulguları}

Deneysel Çalışmalar; Balıkesir yöresinden getirilen jips örneğinin karakteristik özelliklerini belirlemek amacıyla MTA(Maden Tetkik Arama) Laboratuarlarında yaptırılmıştır. Tablo 2'de Jips örneğinin kimyasal analiz sonuçları gösterilmektedir. Kimyasal analiz sonuçlarına göre; $\mathrm{SO}_{3}$ miktarının \%46,3 ve $\mathrm{CaO}$ miktarının \%32,3 olduğu tespit edilmiştir. Buna göre $\mathrm{SO}_{3}$ ve $\mathrm{CaO}$ değerinin yüksek olduğu söylenebilir. Tablo 3' de Jips örneğinin gerçek yoğunluk analizleri Accupyc 1330 Hc Piknometre Cihazı kullanılarak 2,59 $\mathrm{g} / \mathrm{cm}^{3}$ olarak hesaplanmıştır.

Tablo 2. Jips numunesinin kimyasal analizi(\%)

\begin{tabular}{|c|c|}
\hline $\mathrm{Na}_{2} \mathrm{O}$ & $<0,1$ \\
\hline $\mathrm{MgO}$ & 0,1 \\
\hline
\end{tabular}




\begin{tabular}{|c|c|}
\hline $\mathrm{Al}_{2} \mathrm{O}_{3}$ & $<0,1$ \\
\hline $\mathrm{SiO}_{2}$ & 0,2 \\
\hline $\mathrm{P}_{2} \mathrm{O}_{5}$ & $<0,1$ \\
\hline $\mathrm{K}_{2} \mathrm{O}$ & $<0,1$ \\
\hline $\mathrm{SO}_{3}$ & 46,3 \\
\hline $\mathrm{CaO}$ & 32,3 \\
\hline $\mathrm{TiO}_{2}$ & $<0,1$ \\
\hline $\mathrm{MnO}_{2}$ & $<0,1$ \\
\hline $\mathrm{Fe}_{2} \mathrm{O}_{3}$ & $<0,1$ \\
\hline A.Za. $\left(1050^{\circ} \mathrm{C}\right)$ & $\mathrm{H}_{2} \mathrm{O}: 19,1$ \\
\hline
\end{tabular}

Tablo 3. Jips numunesinin gerçek yoğunluk analizi

\begin{tabular}{|c|c|}
\hline Numune İşareti & Jips \\
\hline Numunenin Geliş Şekli & Kayaç halinde \\
\hline $\begin{array}{c}\text { Numunenin } \\
\text { Kuruma Sıcaklığ }\left({ }^{\circ} \mathrm{C}\right)\end{array}$ & 110,0 \\
\hline Numune Kütlesi $(\mathrm{g})$ & 4,12 \\
\hline Numune Hacmi $\left(\mathrm{cm}^{3}\right)$ & 1,59 \\
\hline Gerçek Yoğunluk $\left(\mathrm{g} / \mathrm{cm}^{3}\right)$ & 2,59 \\
\hline
\end{tabular}

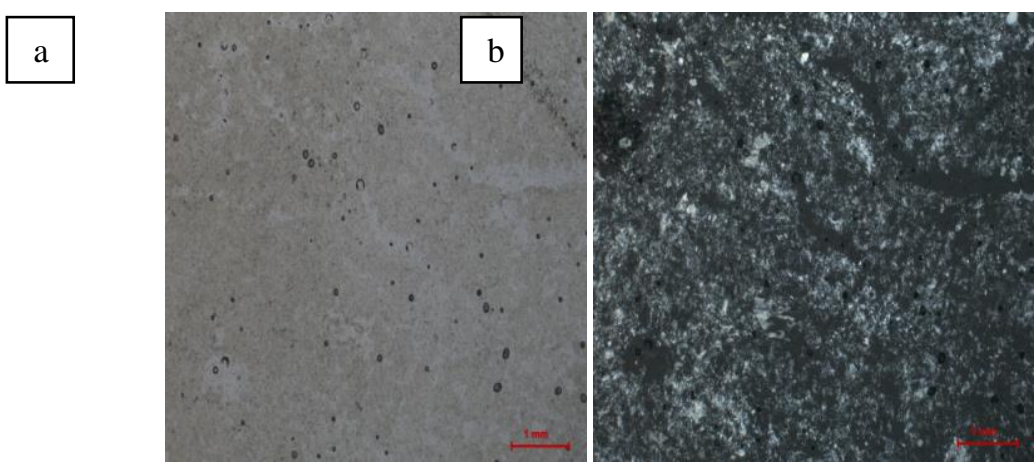

Şekil 1. Jips numunesinin a)tek nikol ve b)çift nikol incekesit görüntüleri

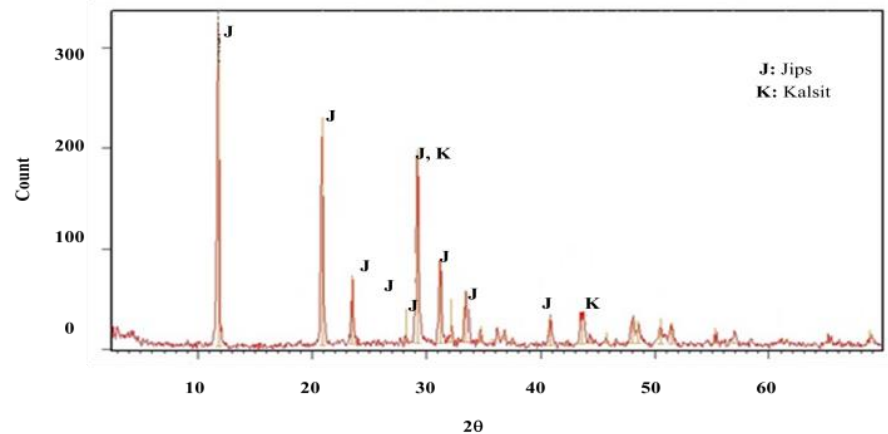

Şekil 2. Jips numunesinin X-Ray difraktometre paterni 


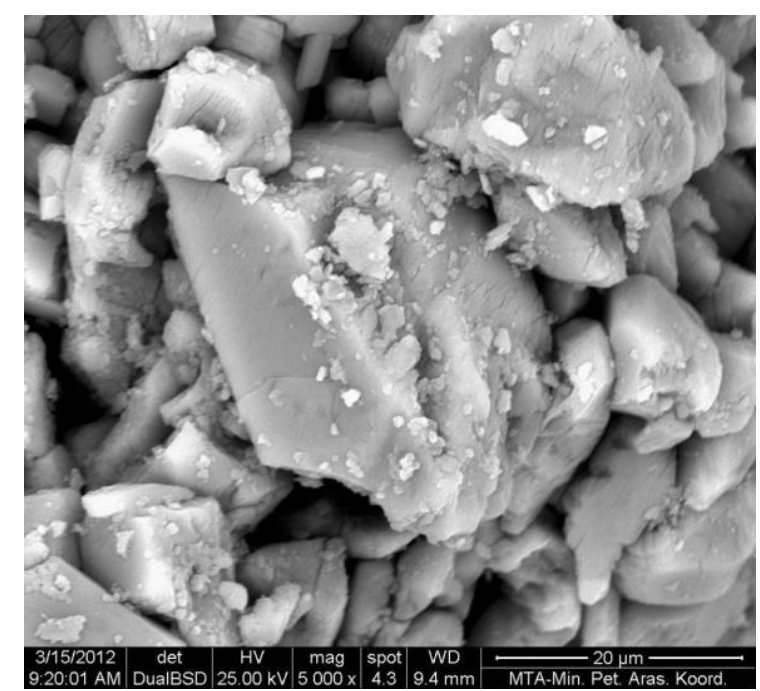

Şekil 3. Jips numunesinin BSE(geri saçılmış elektron mikroskobu) görüntüsü

Şekil 2' de jips numunesinin X-Ray difraktometre paterni gösterilmektedir. Jips örneğinin mineralojik bileşimleri Cu X-1şın tüplü Philips PW 3710/1830 XRD analiz cihazı ile 2-70 arasında gerçekleştirilen XRD(X-1şını difraktometresi) analiz cihazı ile belirlenmiştir. Cevher X-1şınları çekimlerinde ASTM No:33-267 standartlarına göre başlıca jips ve çok az kalsit mineralleri tespit edilmiştir. Şekil 3' te Jips örneğinin BSE(geri saçılmış elektron mikroskobu) görüntüsü ve Şekil 4' te jips örneğinin SEM(taramalı elektron mikroskobu analizleri) analiz görüntüleri verilmektedir. Sonuçlar incelendiğinde; jips minerallerinin ve az miktarda kalsit mineralinin olduğu belirlenmiştir.

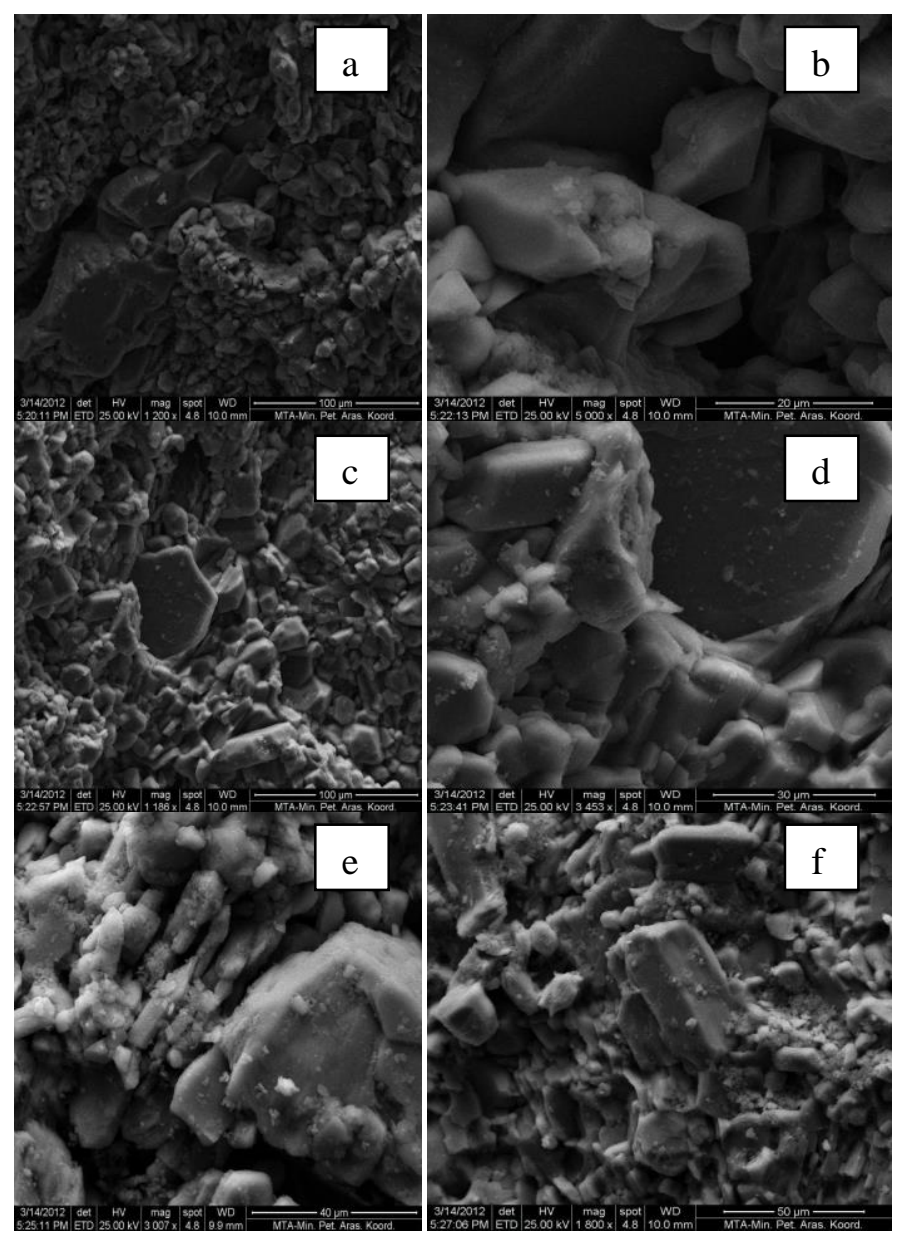

Şekil 4. Jips numunesi genel doku SEM(taramalı elektron mikroskobu analizleri) analiz görüntüleri

\section{Sonuç ve Öneriler}

Çimento yapımı sırasında katkı maddesi olarak erken prizlenmesini önlemek için \%2-6 arasındaki oranlarda jips(alçıtaşı) kullanılmaktadır. Bu çalışma kapsamında araştırılan jipslerin $\mathrm{SO}_{3}$ oranlarının \% 34'ün üstünde olduğu ve çimento sanayi için aranan özelliklere uygun olduğu tespit edilmiştir. Çalışma alanında yayılımları belirlenmiş olan jipslerin yaklaşık 300 milyon ton rezervi olduğu önceki çalışmalarda belirtilmektedir. Yapılan araştırmalara göre kumlu kiltaşı içerisinde, 10-15 metre kalınlık arasında yer alan boratlı jipslerin olduğu tespit edilmiştir. Jips veya jips-anhidrit karışımlarının farklı oranlardaki sülfat mineralleri; son öğütme 
sürecinde portland çimentosu klinkeri içerisine katılmaktadır. Sülfat minerallerinin eklenmesi ile çimentonun donma zamanının kontrolü daha rahat bir şekilde sağlanmaktadır. Çimentonun öğütülmesi sırasında kullanılan bu mineraller \% 3-5 oranlarında kullanılmaktadır. Bu çalışmada araştırılan jips numunelerinin örneğin traslı çimento ve yüksek firın cüruflu çimento yapımında kullanımına elverişli olduğu sonucuna varılmıştır.

Traslı çimento (ağırlık olarak 20-40'lık tras ile 80-60'lık portland çimento klinkeri bir miktar alçı taşı ile öğütülerek hidrolik bağlayıcı elde edilir) tuzlu, alkali ve agresif sulara karşı dayanıklı olması nedeni ile temel ve tünel inşaatlarında, baraj inşaatlarında, kütle beton inşaatlarında, zirai ve sanayi tesis inşaatlarında kullanılmaktadır. Yine yüksek firın cüruflu çimento (ağırlıkça 20-80' lik portland çimento klinkeri 80-20' lik yüksek fırın cürufu ve bir miktar alçıtaşı ile öğütülmesi ile hidrolik bağlayıcı elde edilir.) çok etkili korozyonların olmadığı yerlerde kullanılmaktadır[18].

\section{Kaynaklar}

[1]. Bates, R. L., 1969. "Geology of the Industrial Rocks And Minerals", Dover Publications, New York, 459 s.

[2]. İstanbulluoğlu, Y. S., 1997. "Alçıtaşı ve Anhidrit Üzerine Bir Çalışma" Madencilik Dergisi, Haziran-Eylül, $36,2-3$.

[3].http://bilimkentmadencilik.com.tr/urunlerimiz.html(erişim:01.10.2018)

[4].http://cevherhazirlama.com/belgeler/endustriyel_hammaddeler.pdf (erişim tarihi 01.10.2018)

[5].http://www.maden.org.tr/meslegimiz/oik626.pdf(erişim:10.10.2018)

[6].http://www.marbleport.com/dogal-kaynaklar/89/alitasi-jips (erişim:10.10.2018)

[7].https://www.gelgez.net/alci-nedir-alci-nasil-olusur-ozellikleri-nelerdir-nerelerde-kullanilir(erişim: 10.10.2018)

[8]. http://alcitasijps.blogspot.com/(erişim:10.10.2018)

[9].http://www.balikesir.gov.tr/madencilik (erişim:10.10.2018)

[10]. Çayırlı, H., 1991. "Alçıtaşı ve Türkiye Alçıtaşı Yatakları", Ulusal Alçı Kongresi Bildiriler Kitabı, İstanbul, s. 7 -14.

[11]. Helvacı, C, "Kestelek ve Sultançayır Borat Yataklarının Mineral Toplulukları ve Oluşumları", Ahmet Acar Jeolojisi Simpozyumu. Ç.Ü. Müh. Mim. Fak.Jeo.Müh.Böl., Adana, 1989.

[12]. Gündoğan İ., Helvacı C., 1993, "Sultançayır (Susurluk-

Balıkesir) Boratlı Jips Havzasının Jeolojisi, Mineralojisi Ve Ekonomik Potansiyeli" Türkiye Jeoloji Bülteni, C. 36,159-172, Geological Bulletin of Turkey, V. 36, 159-172.

[13]. http://www.jips.info.tr/(erişim tarihi 10.10.2018)

[14].http://www.naturpa.com/?newUrun=1\&Id=1113607\&CatId=bs417595\&Fstate=\&/Toprakd\%C3\%BCzenleyici-(Bereket-Jips) (erişim tarihi 08.10.2018)

[15]. http://www.mta.gov.tr/v3.0/bilgi-merkezi/alci-tasi (erişim tarihi 10.10.2018)

[16]. http://www.hccmaden.net/jips-alci-tasi/(erişim:10.10.2018)

[17]. Appleyard, F. C., 1975. "Gypsum and Anhydrite", Industrial Minerals and Rocks, New York, s. 185-199.

[18].http://www.mabetas.com.tr/p42-hazir-beton-bilesenleri (erişim: 12.10.2018) 